\title{
Table Device
}

National Cancer Institute

\section{Source}

National Cancer Institute. Table Device. NCI Thesaurus. Code C50371.

A piece of furniture having a smooth flat top that is usually supported by one or more vertical legs, or any object of a similar appearance. 